QoL by EHRA Class

(Utility multiplied by 100 for display purposes)
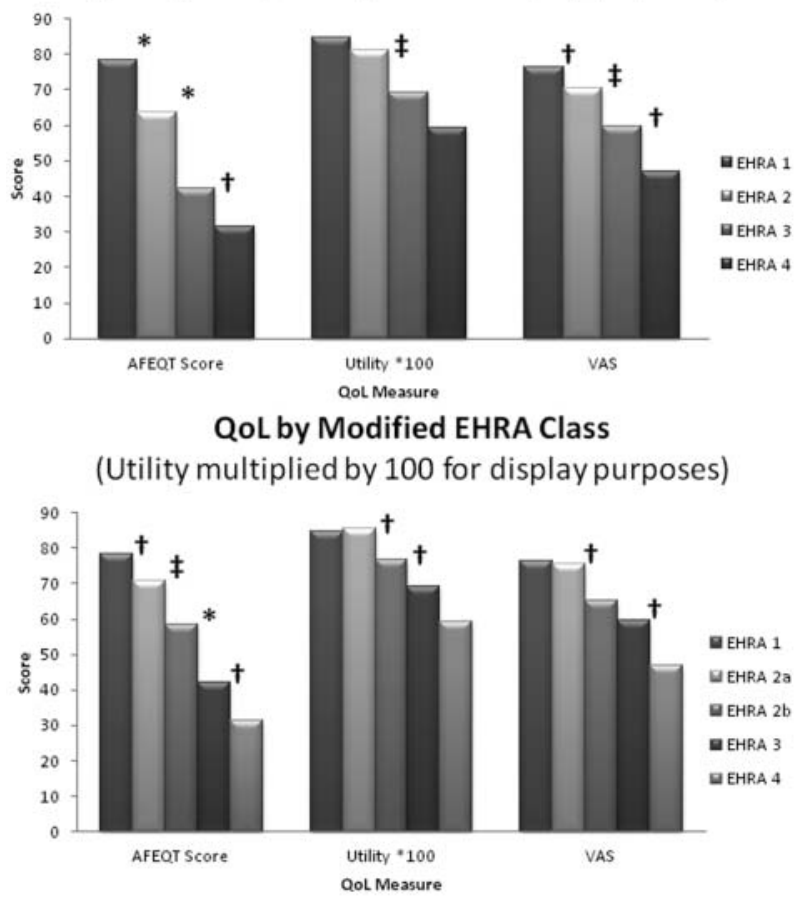

Significance $\uparrow<0.05 \ddagger<0.001 *<0.0001$

Figure 1

Table 1

066

\section{MODIFICATION OF THE EUROPEAN HEART RHYTHM ASSOCIATION AF SYMPTOM SCORE IMPROVES DISCRIMINATIVE ABILITY: A VALIDATION STUDY}

G J Wynn, M Webber, D Cullen, T Hutson, S M Modi, S J Pettit, N M Hawkins, D Barker, M C S Hall, R Snowdon, J E P Waktare, D M Todd, D Gupta Institute of Cardiovascular Medicine and Science

\section{doi:10.1136/heartjnl-2013-304019.66}

Introduction The European Heart Rhythm Association (EHRA) Score for symptoms in Atrial fibrillation (AF) was proposed in 2007 but thus far has not been validated, yet features in European Society of Cardiology 2010/2012 guidelines. Anecdotally, many clinicians feel the jump from class 2 (mild) to class 3 (severe) misses an important step (moderate) where intervention may be more likely to be considered.

Methods Consecutive patients identified as having AF as their primary consultation reason for attending Heart Rhythm clinics at a large cardiovascular centre in the UK completed general (EQ5D) and AF-specific (AFEQT) Quality of Life ( $\mathrm{OoL}$ ) questionnaires. EHRA score was documented by the reviewing clinician, or retrospectively from clinical notes. Patients initially classified EHRA 2 were subsequently re-classified by two clinicians blinded to $\mathrm{QoL}$ scores as either 2a (mild: Normal daily activity not affected and symptoms not considered troublesome by patient) or $2 \mathrm{~b}$ (moderate: Normal daily activity not affected but patient troubled by symptoms).

Results QoL and symptom data was collected on 362 patients (59\% Paroxysmal, 65\% Male). Mean QoL scores by EHRA Class are shown in the table and ilustrated in the graph with degree of statistical difference ( $t$ test) shown at each grade boundary. There is an

\begin{tabular}{lll}
\hline $\begin{array}{l}\text { Modified EHRA } \\
\text { Class }\end{array}$ & Symptoms & Description \\
\hline 1 & None & N/A \\
$2 \mathrm{a}$ & Mild & $\begin{array}{l}\text { Normal daily activity not affected and symptoms not } \\
\text { considered troublesome by patient }\end{array}$ \\
$2 \mathrm{~b}$ & Moderate & $\begin{array}{l}\text { Normal daily activity not affected but patient troubled by } \\
\text { symptoms }\end{array}$ \\
3 & Severe & $\begin{array}{l}\text { Normal daily activity affected } \\
\text { Normal daily activity discontinued }\end{array}$ \\
\hline
\end{tabular}

important stepwise progression in the AFEQT score as patients progress from EHRA Class 1-4 with a significant difference between $2 a$ and $2 b$ in all QoL measures.

Conclusions Based on AFEOT score and EQ5D Visual Analogue scale this study provides the first validation of the EHRA score. The Modified Score improves discriminative ability and, importantly, health utility is significantly different at the $2 a / 2 b$ and $2 b / 3$ boundaries, where decisions about AF ablation are likely to be made. Based on utility; invasive treatment for patients graded $2 b$

Table 2

\begin{tabular}{llll}
\hline EHRA Class (n) & AFEOT overall & Utility (by EQ5D) & Visual analogue score \\
\hline $1(149)$ & $78.4( \pm 19.0)$ & $0.85( \pm 0.21)$ & $76.2( \pm 19.9)$ \\
$2 \mathrm{a}(45)$ & $70.9( \pm 19.8)$ & $0.86( \pm 0.18)$ & $75.6( \pm 19.9)$ \\
$2(99)$ & $63.6( \pm 20.0)$ & $0.81( \pm 0.17)$ & $70.3( \pm 20.3)$ \\
$2 \mathrm{~b}(44)$ & $58.3( \pm 17.3)$ & $0.77( \pm 0.15)$ & $65.1( \pm 20.1)$ \\
$3(90)$ & $42.1( \pm 21.1)$ & $0.69( \pm 0.27)$ & $59.6( \pm 21.9)$ \\
$4(24)$ & $31.3( \pm 18.6)$ & $0.59( \pm 0.29)$ & $46.9( \pm 25.9)$ \\
\hline
\end{tabular}


BCS Abstracts 2013

Table 3

\begin{tabular}{|c|c|c|}
\hline $\begin{array}{l}\text { Modified EHRA } \\
\text { class }\end{array}$ & Symptoms & Description \\
\hline 1 & None & $\mathrm{N} / \mathrm{A}$ \\
\hline $2 a$ & Mild & $\begin{array}{l}\text { Normal daily activity not affected and symptoms not } \\
\text { considered troublesome by patient }\end{array}$ \\
\hline $2 b$ & Moderate & $\begin{array}{l}\text { Normal daily activity not affected but patient troubled by } \\
\text { symptoms }\end{array}$ \\
\hline 3 & Severe & Normal daily activity affected \\
\hline 4 & Disabling & Normal daily activity discontinued \\
\hline
\end{tabular}

(or above) is likely to be more cost effective than those graded $2 \mathrm{a}$ (where the potential improvement to Class 1 is minimal). We recommend adoption of the modified system, and propose that EHRA $2 \mathrm{~b}$ be considered the cut point for treatment decisions. 